\title{
Gold in the Pottery Industry
}

\section{THE HISTORY AND TECHNOLOGY OF GILDING PROCESSES}

\author{
L. B. Hunt \\ Johnson Matthey \& Co. Limited, London
}

\begin{abstract}
The gilding of porcelain has been practised from the earliest days of its production, the permanence and brightness of gold naturally appealing to designers and manufacturers. Nowadays some five tons of gold are required annually for the decoration of porcelain and earthenware, and this article recounts the developments in gilding from the early closely guarded secret recipes to the current techniques involving not only some very complex organic chemistry but also a considerable degree of ingenious mechanisation of the processes, although the role of the skilled hand gilder is still in evidence on more expensive productions.
\end{abstract}

The gilding of porcelain and pottery - ranging from the simple edging on a plate to the elaborately decorated vase with richly gilt panels and scrolls has always been a prominent feature. It is more than 250 years since the introduction of chemical methods of preparing gold in a powder form suitable for application to porcelain led to the replacement of the old procedure, used first in China, of simply applying gold leaf over a layer of linseed oil and litharge, or with egg white or shellac. It is 150 years since the first gold preparation in liquid form was devised, bringing with it the much wider and more economical use of gold in the pottery industry.

The history of these developments is one of jealously guarded secret recipes with the supposed secrets often being spread by the migration of skilled workers from one factory to another. On occasion, however, there were major contributions from one or two distinguished scientists.

\section{Johann Friedrich Böttger 1685-1719}

The thousand year old secret of Chinese porcelain was rediscovered by Böttger, a young apothecary and alchemist who had fled from the court of King Frederick I of Prussia only to be imprisoned in Dresden by Augustus the Strong, Elector of Saxony, an assiduous collector of china. At first he was commanded to make gold from base metals, but in 1707 his master ordered him to attempt the production of porcelain. He then placed over the doorway of his laboratory a notice:

'God our creator has turned a gold maker into a potter'. He produced the first unglazed porcelain in 1709 and in the following year the famous Meissen factory was established. Worn out by his exertions and his hardships, however, Böttger died at the early age of $\mathbf{3 4}$ before a really successful method of gilding had been developed
The preparations in use today fall into three main groups. Modern liquid golds are formulated from an organo-gold compound containing a sulphur linkage, such as a gold sulpho-resinate or thiolate. The addition of small amounts of other metals, including bismuth, chromium, vanadium and rhodium, also as their sulpho-resinates or similar compounds, is necessary to secure both good adhesion of the gold film to the glaze and stability during the firing operation, while the solvents comprise either natural or synthetic materials - essential oils, chlorinated cyclic

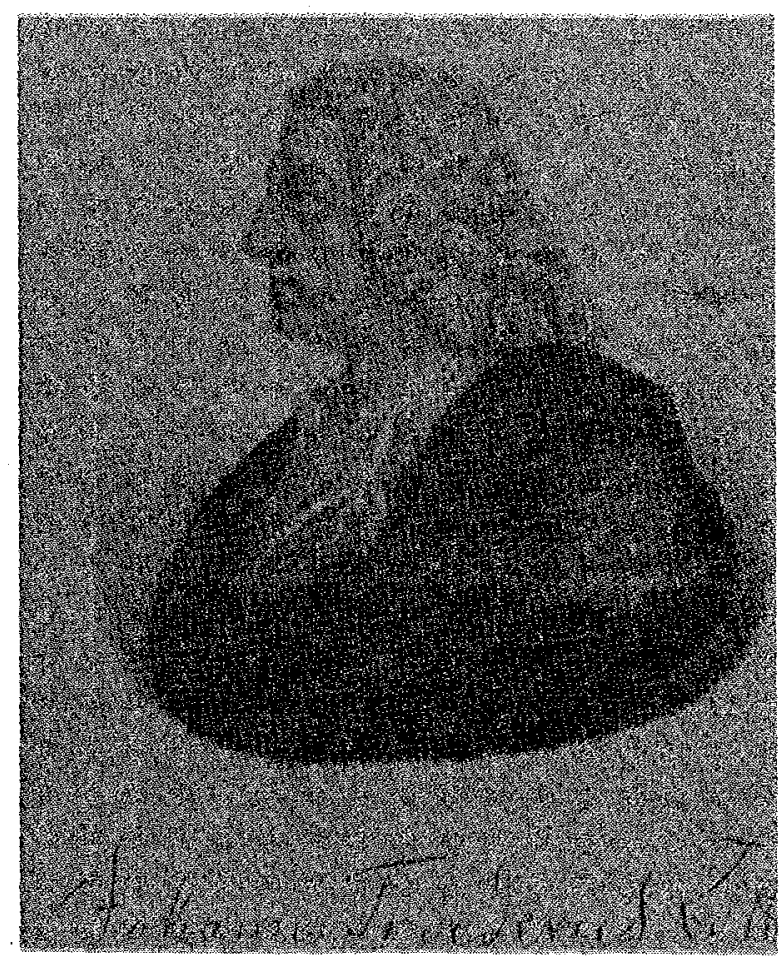


A Meissen plate, one of a travelling tea-set, made in about 1730 and now in the British Museum. This is one of the earliest examples of the high quality of fired gilding introduced there

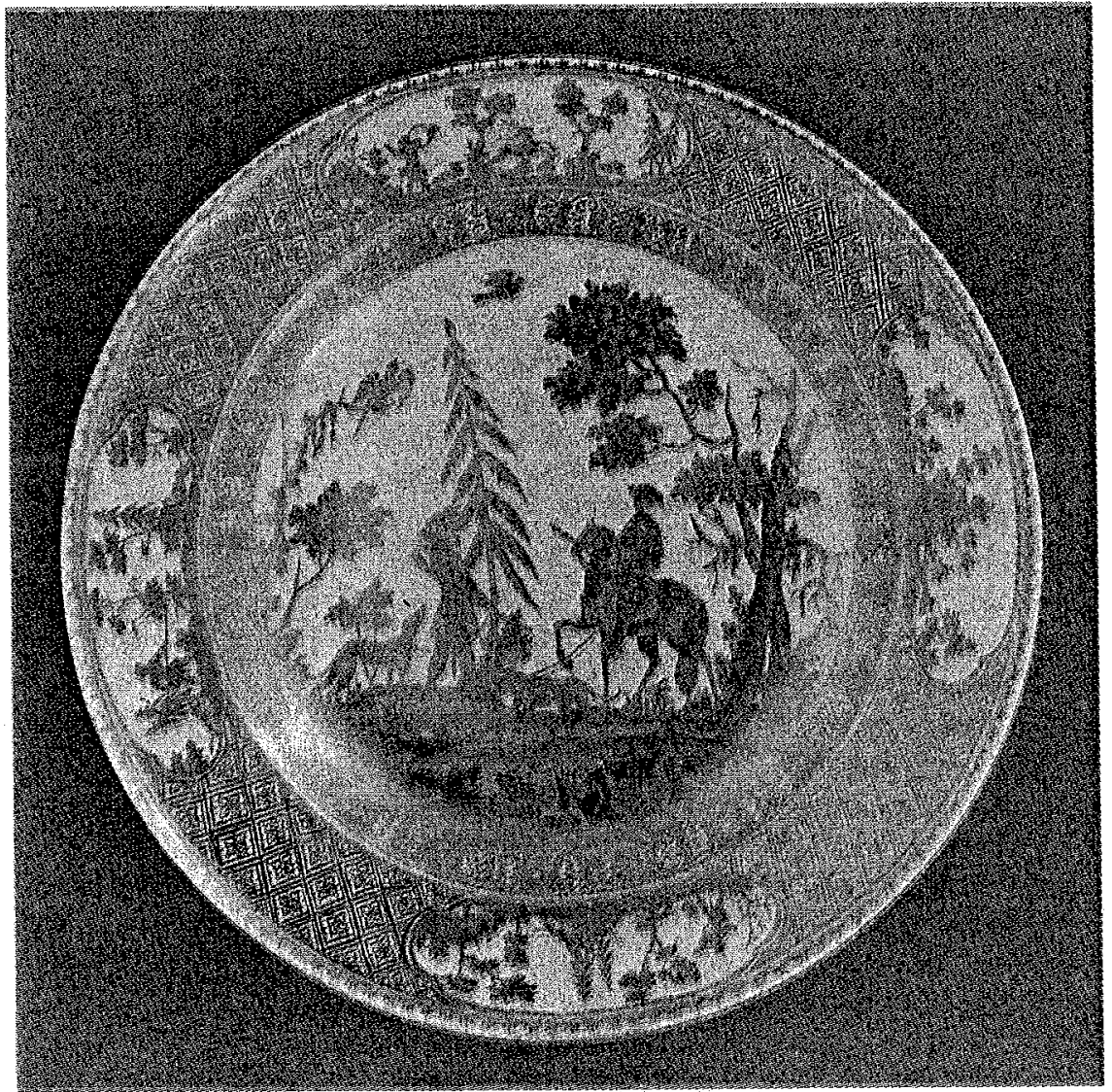

hydrocarbons or glycol esters, with resins such as glyceryl abietate. The basic organic gold compounds are extremely complex and of very high molecular weight.

Secondly, the older types of preparation in powder form are still relied upon extensively for heavier and more expensive gilding, while the third group consists of preparations containing the gold in solution but with the addition of a proportion of gold in powder form to provide the so-called liquid burnish golds or matte golds.

\section{The First European Porcelain}

To return to the earliest days of European porcelain; when Johann Friedrich Böttger, virtually imprisoned by the Elector of Saxony, finally succeeded in 1709 not only in finding the right materials for the porcelain body but in building a kiln capable of giving him a temperature high enough to fire his ware, he naturally began to turn his mind towards its decoration. In the first few years, gilding was carried out by the old method of applying gold leaf by means of a lacquer, without firing, but this was of course easily abraded so that very few examples have survived.

Where then did Böttger turn to find a reliable means of gilding? There was in fact open to him one excellent source of information on the likely aspects of gold chemistry. Böttger, born in Schleiss in Saxony in 1685 , was apprenticed at the early age of 12 to an apothecary named Zorn in Berlin, and at night he indulged his alchemical ambitions in the apothecary's laboratory. In these experiments he was encouraged by a much older man, Johann Kunckel, a friend of the Zorn family who was often in their house. As well as being something of an alchemist Kunckel was the most advanced chemist of the seventeenth century and a prolific writer of text books. (Curiously he had earlier been in the service of Johann Gregor II, Elector of Saxony, the grandfather of Augustus the Strong, Böttger's autocratic employer). Kunckel had published in 1679 his 'Ars Vitraria Experimentalis oder Vollkommene Glasmacher-Kunst', a complicated work based initially on the 'L'Arte Vetraria' of the Florentine priest Antonio Neri, written in 1612, and translated into English and dedicated to Robert Boyle in 1662 by Christopher Merrett, who appended a number of observations of his own. Kunckel's book was in effect a German translation of these two works, followed by a lengthy section of his own, and it was in this latter part that he included a chapter on the gilding and enamelling of glass which he reproduced from an unknown work, the author of which, he says, 'had himself been a good glass painter, according to his information had recently died, but of unknown name except that he wrote as H.I.S.'. 


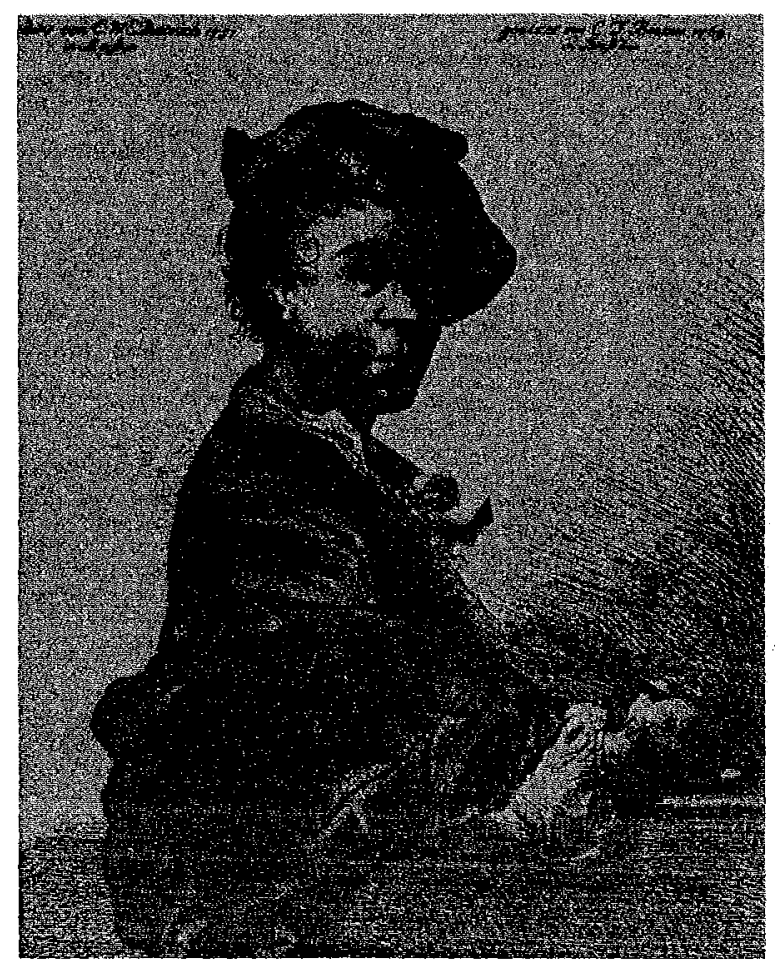

In the course of this chapter, no less than sixteen recipes were given for the gilding of glass, most of them describing merely the sticking on of gold leaf, but a few involving heating the gilded ware in a coal fire 'so it never comes off'.

It is a fair assumption that Böttger was well aware of this book and almost certainly possessed a copy of his own. But by the time he was wrestling with the problem of gilding in a more reliable way, a further work of Kunckel's became available. This was his 'Laboratoria Chymica', published in Hamburg and Leipzig in 1716, some thirteen years after the author's death but happily coinciding with Böttger's needs. Here, among other observations on the

\section{Johann Gregorius Höroldt}

\section{6-1775}

Sometimes referred to as the father of European porcelain decoration, Höroldt was born in Jena, the son of a tailor. In 1718 he entered the newly established porcelain factory in Vienna but two years later left for Meissen, together with Samuel Stöltzel (who had escaped from Meissen with his secrets in 1719 but returned dissatisfied) and who recommended him as 'a well trained and experienced decorator'. His remarkable talents quickly enabled him to prepare a complete palette of enamel colours and to devise a reliable method of gilding that was used for very many years. This portrait is from an etehing by $C$. W. E. Dietrich made in 1731 and preserved at Meissen

chemistry of gold, Kunckel described the precipitation of gold powder by the addition of a solution of ferrous sulphate to a solution of gold in aqua regia to give 'a quite beautiful and very fine precipitate'. It was this form of gold powder that was to put Böttger and his successors at Meissen in a position to establish a sound procedure for the gilding of porcelain. Although, as will be seen, quite different methods were adopted in other porcelain factories from time to time, the ferrous sulphate precipitate remained for over two hundred years the basic starting material in England as well as in Germany, and is still used to some extent in the preparation of modern burnish golds.

\section{Johann Gregorius Höroldt}

Although Böttger had succeeded in gilding his porcelain with lightly fired gold, and had outside decorators carry out gilding by the methods of the glass workers, he did not see really durable gold applied to his porcelain before his untimely death in 1719. It was not in fact until about 1723 that reasonably good gilding became a feature of Meissen porcelain, and for this the credit must be given to

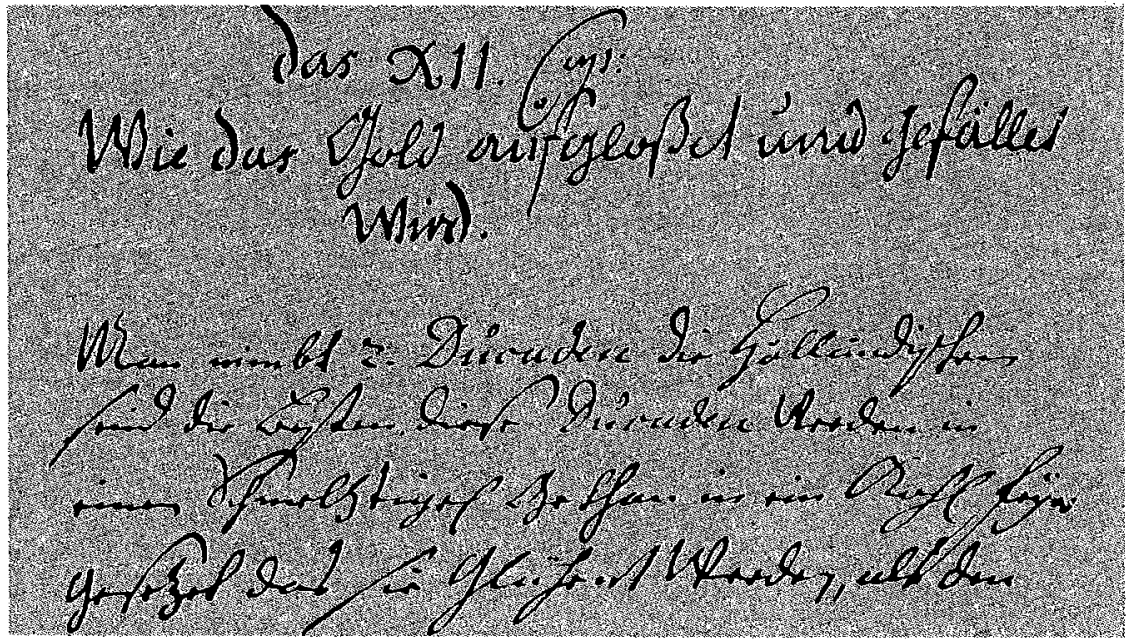

The opening paragraph of Chapter XII of Höroldt's note-book, compiled in 1731. The tille reads 'How the Gold is to be Dissolved and Precipitated' and goes on to detail the procedure for dissolving Dutch ducats in aqua regia and precipitating the gold with a solution of ferrous sulphate

Photograph by courtesy of the Archive Department of the National Porcelain Factory, Meissen 
Johann Gregorius Höroldt, who arrived at Meissen from Vienna in 1720 as a young painter and enameller. It is likely that Höroldt found some manuscript notes of Böttger's dealing with his attempts to produce enamel colours and gold decoration, although nothing of this kind has survived, but in any case, and in a most remarkable way, Höroldt soon acquired a sound knowledge of contemporary chemistry, sufficient at least for him to develop a range of enamel colours and a procedure for gilding that helped to create the full artistic flowering of decoration on European porcelain.

In 1731 the administrators of the Meissen factory asked Höroldt and his colleagues to put on record the recipes for their palette, and the small parchment note-book he compiled at this time is preserved in the archives there. Dated December 24, 1731, the notebook entries are introduced with this sentence:

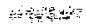

'True and correct description of enamel or vitrifiable colours which I have invented with God's help and which are used by the local porcelain factory, also the gold and silver decoration and how such have to be treated'.

In the section on gilding, Chapter XII, running to some ten pages and headed 'How the Gold is to be Dissolved and Precipitated', Höroldt begins:

'One takes two ducats, the Dutch are the best, they are easie to cut and also the aqua regia attacks the gold better'.

He chose well, because at that time the Dutch ducat had the highest gold content of any coinage in Europe, 237/8 carat, or 98.6 per cent. The solution of the ducats was then to be poured slowly into a filtered and diluted solution of 'Hungarian vitriol' (ferrous sulphate), stirring with a clean quill to avoid the formation of larger particles of gold. The precipitate, separated by decantation with hot water and then dried, was thoroughly mixed with a finely ground lead silicate flux and applied to the ware. The gold decoration was fired before the colours were applied and finally burnished with pieces of flint.

After decorating with colours, the gold naturally became dull and had to be burnished again, but Höroldt emphasises that the first polishing was still necessary to make the gold 'even more beautiful'.

This then was the basis of the brilliant gilding that characterised early Meissen porcelain, the gold decoration becoming more elaborate by about 1740 . But the Seven Years' War brought to an end the domination of Meissen, and when Frederick the Great of Prussia occupied Dresden in 1762 he took the moulds and models, together with some of the leading workers, to the Berlin Porcelain factory which he then purchased for himself. Undoubtedly the same procedure for gilding was used in Berlin and a number of smaller factories established in Germany as well as in the Vienna factory that had been set up in 1717 with the help of two runaway workers from Meissen and where Samuel Stöltzel, Böttger's kiln master at Meissen, spent a year in 1720 until his return to Meissen bringing Höroldt with him. One of Stöltzel's recipe books has also survived and includes a description, rather less precise than Höroldt's, of the dissolution of gold and its precipitation with ferrous sulphate.

\section{Gilding at Vincennes and Sèvres}

A very different approach was adopted in the early years of porcelain production in France, and there seems to have been no knowledge of the precipitation technique so successfully employed in Saxony. As early as about 1690 a type of porcelain was being made at St Cloud, and there is a well known reference to the successful gilding of the ware in a book written by Dr. Martin Lister, later physician to Queen Anne, in the course of his visit to Paris with the Duke of Portland in 1695:

'I saw the potterie of St Clou with which I was marvellously well pleased ... They had arrived at Burning on Gold in neat Chequer Works'

This extraordinarily early record of 'burning on' the gold was not however the true gilding process that we are considering here but merely involved applying gold leaf with an iron tool as used by book binders with the aid of a kind of gum made from quince seeds and then passing the ware through the kiln again.

The second porcelain factory to be set up in France was at Chantilly in 1725 under the patronage of Louis-Henri de Bourbon, Prince de Condé, with one Ciquaire Cirou who had earlier worked at St Cloud, but the major development was of course the establishment of the Vincennes porcelain works in 1738 when Orry de Fulvi, brother of the ControllerGeneral of Finance to Louis XV, secured the services of Gilles and Robert Dubois from Chantilly and through his brother's influence obtained the use of buildings attached to the Chateau de Vincennes. The Dubois brothers were unsuccessful and were shortly dismissed and replaced by Francois Gravant, also from Chantilly. Gravant brought with him a recipe for gilding which, although not altogether successful, formed the basis of French gilding technique for very many years. Gold leaf was to be ground to powder on a slab with fine starch and a very little white of egg, well washed with water several times and then dried. To apply the gold to the porcelain a mordant of either gum or a mixture of fine sand and litharge was used.

By 1745 a successful 'soft-paste' porcelain was being produced, and a monopoly was obtained from Louis XV for the manufacture of porcelain after the style of Meissen, forbidding any other establishment 


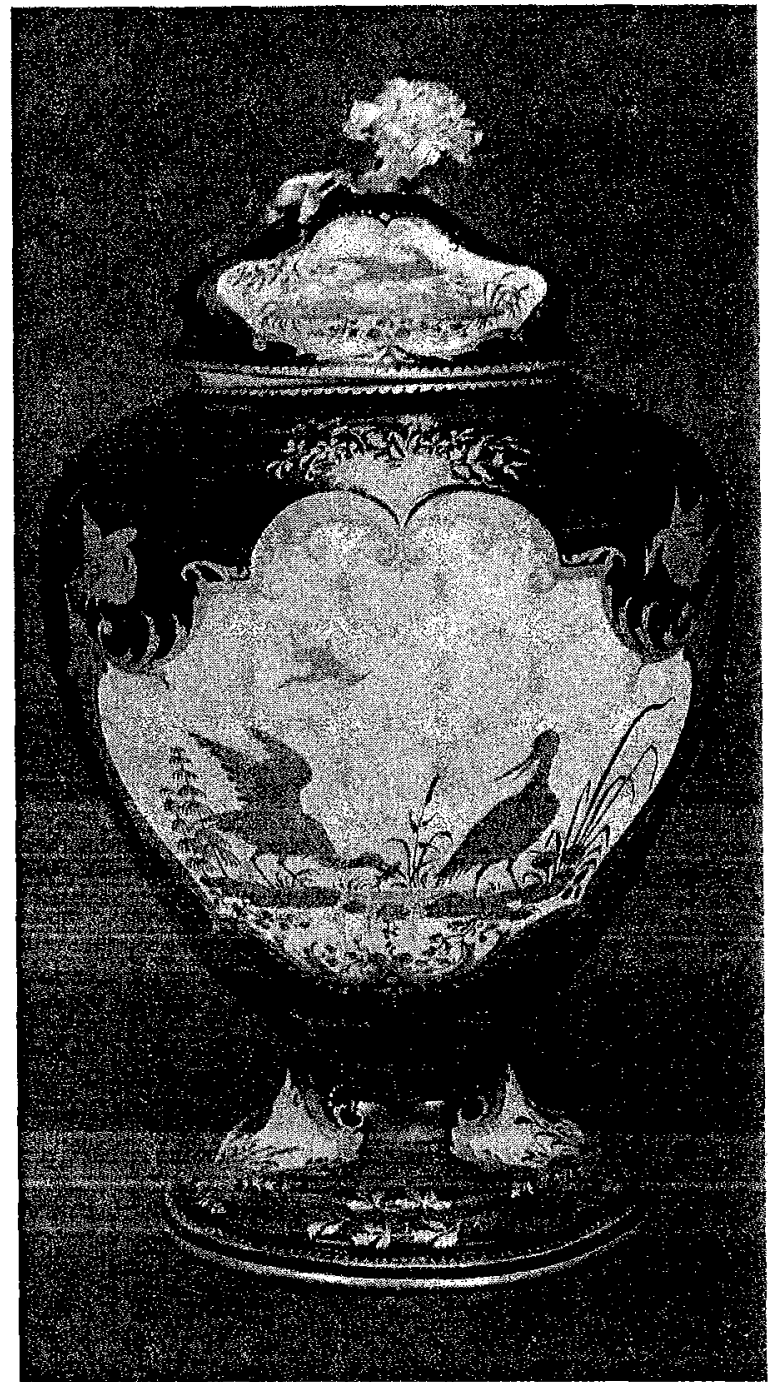

to be set up for the making of porcelain and also restricting the use of gilding to Vincennes. Orry de Fulvi was not, however, satisfied with the gilding technique and in 1748 he purchased a 'secret formula' from Brother Hypolite, a Benedictine monk in the priory of St Martin des Champs in Paris, for the large sum of three thousand livres in cash and an annual payment of six hundred livres.

\section{Jean Hellot and the Monk's Secret Formula}

The factory was now in financial difficulties, and the king's mistress, Madame de Pompadour, herself greatly interested in porcelain and anxious to encourage its production under her own patronage, persuaded Louis to invest heavily in the enterprise, and eventually to take control, the factory then becoming the Manufacture Royale de Porcelaine.

In 1751 Orry de Fulvi died and a number of new appointments were made, the most important from our present point of view being that of Jean Hellot as chemist. Hellot (1685-1766) was one of the foremost
A blue vase and cover made at Vincennes in about 1750 and now in the British Museum. It is thickly decorated with gold, but by a technique entirely different from that used at Meissen, giving a slightly softer and yellower tone.

chemists of his time, a member of the Academie Royale des Sciences since 1735 and twice its Director in 1751 and again in 1764, elected a Fellow of the Royal Society of London in 1740, and a scientific adviser to the government on dyeing, on chemistry and metallurgy, and the author of a number of works on assaying, on mining and metallurgy and on dyestuffs. He immediately set out to study and improve the colours and glazes at Vincennes, and he was equally quick to investigate the gilding recipe of Brother Hypolite, referring disparagingly to the large amount of money paid 'for his supposed secret. It is he who is in charge of the wine, he's very stupid'.

Hellot's note-books are fortunately preserved in the archives at Sèvres, to where the factory was removed in 1756, a site selected by Madame de Pompadour near her chateau, and contain, among many other records of his work on new colours, an account of his lengthy investigations on gilding (1). After complaining that Orry de Fulvi had erroneously copied Hypolite's formula, he goes on to give 'the true and verified secret of Brother Hypolite's painting gold', which was recorded after he had visited on several occasions during 1751 the Priory of St Martin des Champs to watch Hypolite carry out his process.

First, gold leaf was to be ground on a large porphyry slab or a real turtle shell for some ten or twelve hours in a thick solution of gum arabic in water until reduced to a fine powder, which was to be washed with hot water, then passed through a fine sieve and dried. The 'secret' mordant was then to be prepared by distilling white vinegar over a number of large onions and garlic cloves. Finally the gilders were to take a little of the gold powder, mix it on a shell with the right amount of the mordant, and apply it with a brush. The decoration was allowed to dry before being fired, and was then burnished.

The idea of employing garlic in the mordant, by no means new or secret, is extremely interesting in that one of its major constituents is a sulphur-containing essential oil, and to this day the successful compounding of gold preparations for porcelain and pottery hinges upon the presence of a sulphur linkage to the gold atom. However, recipes using garlic in mordants for the gilding of glass and other materials can be traced back at least to fifteenth and sixteenth century manuscripts, copies of which might well have been available in the library of St Martin des Champs. 
There are subtle but perceptible variations in the appearance of the gilding on porcelain, largely dependent upon the size and shape of the gold particles used. To illustrate the essential differences in procedure at Meissen and at Vincennes and Sèvres, laboratory reproductions of their formulae were carried out in the Johnson Matthey Research Centre. These scanning electron micrographs, at a magnification of 1000, show the gold preparations after firing but before burnishing.

Top: Gold powder precipitated from solution in aqua regia by ferrous sulphate, as practised in the early years at Meissen. The rather coarse round particles gave a somewhat duller appearance than later techniques

Centre: At Vincennes and later at Sèvres, gold leaf was laboriously ground up in honey, a viscous medium simply used to avoid the particles adhering to one another. The honey was then washed away and the gold well dried before applying to the porcelain with a mordant. The flat particles produced in this way gave the gilding a softer and slightly more yellow appearance

Bottom: About 1780, a very different and less expensive method was adopted at Sèvres. Gold was precipitated from its solution in aqua regia by adding a solution of mercurous nitrate, this method yielding a very much finer and more flocculent precipitate than ferrous sulphate. The resultant gilding was thinner, less durable and tended to show a rather brassy appearance

Cennino d'Andrea Cennini's 'Il Libro dell'Arte', for example, compiled in Florence just after 1400, describes a mordant for gilding with garlic bulbs, while the 'De Secreti' of Allessio Piemontese, written in Venice in 1555, also contains a recipe for gilding using gold leaf ground up in honey with a mordant based upon garlic and vinegar.

None the less, Brother Hypolite's formula was in use for a long period for the superb and lavish gilding at Vincennes and Sèvres, the monk himself preparing the gold and the mordant, but honey was eventually subtituted for the gum arabic as the viscous medium in which the gold leaf was ground.

Compared to Meissen gilding - on a true hardpaste porcelain - this procedure was successful enough, and probably essential on the soft-paste of Sèvres as it needed only a relatively low firing temperature. A slight but perceptible difference can be discerned between the gilding on Meissen and Vincennes or early Sèvres porcelain, the latter being slightly more yellow and softer in texture. The electron micrographs on this page clearly show the dissimilarity in the shape of the gold powders used.

True hard-paste porcelain was not made at Sèvres until 1772, the necessary research owing a great deal to another famous chemist, Pierre-Joseph Macquer (1718-1784), who had joined Hellot as his assistant in
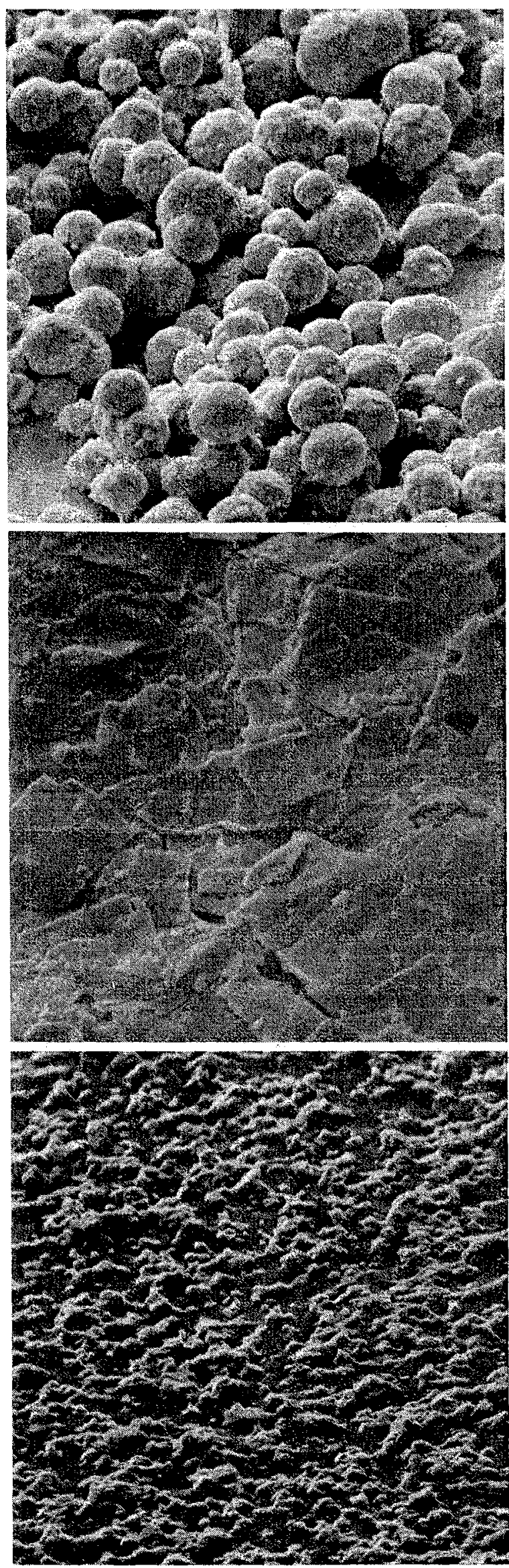
1757 and had succeeded him two years later. This posed the problem of finding a new method of gilding, and the new director, Melchior-Francois Parent, also appointed in 1772 , concerned too at the high cost of the older method, sought for an alternative. By this time the ferrous sulphate precipitate had become known in France, and Parent, in a memorandum preserved in the archives at Sèvres, wrote that 'gold dissolved and precipitated from aqua regia is always more attractive and has a brighter colour' but was less ductile and, compared with the existing procedure, consumed more gold for a given number of pieces of porcelain. He proposed a method employed by metal gilders, dissolving gold in mercury - which had first to be carefully purified evaporating the excess mercury and separating the amalgam in nitric acid to leave a fine gold powder.

The gilders very soon objected to this method, partly because of the danger to their health in evaporating the mercury but also because of the high cost compared with the precipitation method and the less attractive appearance of the gilding. In a memorandum submitted to the management, they insisted that with their then existing method, presumably a precipitation, the gold was much finer, presented no difficulties in use and gave a perfect appearance on hard porcelain, while they maintained that for soft porcelain (which continued to be made alongside the new hard body until 1804) neither a precipitated gold powder nor one made with mercury would ever be suitable and that the old technique of grinding gold leaf was essential.

\section{The Mercurous Nitrate Method}

However, a still further procedure was soon to be adopted for hard-paste porcelain. If instead of using a solution of ferrous sulphate one of mercurous nitrate is employed, a much finer and more flocculent precipitate is obtained, while a small amount of mercury compound is occluded in the gold powder, a factor that assists materially in securing good adhesion and in reducing to some extent the temperature of firing. The date of the inception of this method is difficult to establish with accuracy, but a valuable clue is contained in a memorandum dated 1781 from Jean-Jacques Bachelier - a protégé of Madame de Pompadour who was artistic director for over forty years - to the Comte d'Angiviller who had succeeded Parent as director at Sèvres in 1778 when the latter was imprisoned for misappropriating funds. Bachelier refers to the great expense of the enormous quantity of gold being used, and to the poor taste of some of the gilding, and goes on:

\footnotetext{
'There are only two methods of gilding porcelain. Should there not be a third? We have some good ideas on this possibility: there are interesting experiments to be made' (2).
}

It can be assumed then that sometime in the midde of the 1780's this new method was adopted at Sèvres. The precipitated gold, well washed of course and dried, was used with a mixture of bismuth oxide, borax and turnpentine to assist in adhesion to the harder glaze. The greater degree of fineness of the gold particles precipitated in this way is clearly shown in the electron micrograph on page 121 .

This was the preferred method used for very many years on hard porcelain at Sèvres. Some sixty years later, Alexandre Brongniart, the scientist appointed as director by Bonaparte in 1800 , wrote that this was the method generally employed and that, although compared with the ferrous sulphate precipitate it was more economical and gave a much finer powder, it did not withstand usage so well and often a double application, with burnishing before and after the second treatment, was found necessary (3).

The ferrous sulphate precipitate, however, yielded a more solid appearance to the gilding despite the expense of the considerably greater quantity of gold used. Brongniart adds an amusing note on the production of imitations of very old Sèvres porcelain by the addition of traces of copper to the honey-ground gold 'to give a dull appearance to the gilding which amateurs attribute to the antiquity of the piece'.

\section{The Factories at Limoges and Tournai}

After the introduction of hard-paste porcelain at Sèvres the restrictions on others and the prerogative on the use of gold were gradually relaxed, and a number of porcelain factories blossomed forth in France, several of them under the patronage of the nobility, anxious to associate themselves with porcelain manufacture. One of the earliest was at Limoges, under the protection of the Comte d'Artois, and first followed the Sèvres procedure, grinding in honey and applying the gold to the ware with borax and gum water, but later adopted the ferrous sulphate precipitation method with a bismuth oxide and borax flux mixed with turpentine to give a brighter and more lavish effect. By about the middle of the nineteenth century, however, this method was gradually replaced by the mercurous nitrate precipitate to give a brilliant effect with greater economy (4).

Similarly the eldest son of the Comte, the Duc d'Angoulême, sponsored a porcelain factory in Paris in 1780 with Christophe Dihl as colour chemist. They were quick to profit from the removal of the ban on gilding imposed by Sèvres, and they were to have an influence on the techniques adopted by the famous Worcester factory in England.

Before this, however, an important factory had been established at Tournai in Belgium and was producing soft-paste porcelain by 1751 . Tournai was sufficiently remote from Paris to be able to ignore the 
prohibition on gilding, and its porcelain displayed thick and rich gilding, almost certainly by means of the early procedure used at Vincennes and Sèvres, the grinding of gold leaf in honey. One of the important features of Tournai, however, was its link with the Chelsea factory in London, founded in about 1743 by Nicholas Sprimont, a goldsmith from Liège, and Charles Gouyn who was a Huguenot and a jeweller. For some years the little gilding used was rather dull in appearance, but by around 1758 a beautifully soft type of gilding made its appearance, resembling that of both Sèvres and Tournai.

This thick soft gilding, equal to the best of continental work, continued to characterise the wares for some time after the Chelsea factory was purchased by William Duesbury of Derby in 1770 .

\section{Josiah Wedgwood's Difficulties}

The early difficulties encountered and solved by the great Josiah Wedgwood are indicative of the uncertainties of gilding methods. Wedgwood set up for himself in Staffordshire in 1759, when only 29 years old, to make earthenware, both useful and ornamental, and his much improved product was soon successful. By 1765 he received his first order from Royalty, for 'a complete sett of tea things, with a gold ground and raised flowers upon it in green' from Queen Charlotte, the wife of King George III. In a letter to his brother John in London dated June 17, 1765, he wrote:

'I have just begun an Enamel work, and am in great want of some gold powder such as is burnt in upon China. It is made by one Mr. Shenton (only) and sold by him at 7 guineas Per oz. Mr. Giles Enameller in Berwick St Soho can tell you where $\mathrm{Mr}$. Shenton lives, which is the best Direction I can get. I should be glad to have a few pennyweights by way of tryal; if it answers well shall want large quantities. Mr. Shenton may perhaps give you instructions about the best manner of using it. What I would be glad to know ... is whether she expects the gold to be burnt in, as it is upon the Chelsea china, or secured with a varnish only, like the Birmingham waiters'.

About a month later, in another letter to brother John, he wrote:

'I am very busy every day preparing sprigs, handles..., making experiments in burning on gold etc., etc. for the service, and from experience I can tell you that the sooner I do 'em the more imperfect they will be... Powder gold would do them for me if I knew how to polish it after it is burnt. There is one Jinks who was a gilder in enamel at the Chelsea works and is now at the Bow China work; if it would not be too tedious I wish you would buy a cream colour enamelled cream Ewer and get Jinks to gild all the spaces but the flowers, etc. and burn the gold in, by which you'll see if he is capable of doing anything for me'.

And again, in a post-script to a letter of August 7:

'I have succeeded the first tryal in making powder gold which I have allways been told one man only in England could make, and desire you'l send me an oz of pure gold either in Ducats or grain or some form, send the powder too' (5).
Naturally enough, Wedgwood being the practical scientist he was, he very soon solved his problems, and a few years later his 'Commonplace Book' includes a short recipe:

'Gilding on Porcelain - 10 parts of Gold powder, and 1 of ceruse - with gum water - Burnt in then Polish with Agate, rubbing always one way'.

By the 1780's his note-books reveal that he was fully aware of all the variations on the gilding process and making use of them.

\section{Gilding on British Porcelain}

The porcelain factory with the longest continuous history in England, the Worcester Royal Porcelain Company, founded in 1751, likewise used gold leaf ground up in honey, washed, dried and applied with a flux, to produce an elegant and thick type of gilding in its earlier period under the famous Dr. Wall. In 1783 the factory was purchased by its London agent Thomas Flight, and a few years later, after a visit by his son John to the Duc d'Angoulême's factory in Paris, a quite different and more economical technique was adopted. This consisted in preparing an amalgam of mercury with 'brown gold', (the ferrous sulphate precipitate, sometimes purchased from the gold refiners), grinding this in turpentine with a glassy flux or with bismuth oxide and applying the mixture to the ware. At a conveniently low firing temperature the mercury was driven off and a matt gold resulted that could be burnished to give a rich and brilliant effect.

This easier and cheaper method of gilding was used by a number of British potteries in Staffordshire and elsewhere for many years until the development of the more scientifically compounded preparations of the last quarter of the nineteenth century. One or two typical recipes confirm the procedure. At the Spode factory in Stoke-on-Trent, for example, where porcelain manufacture began in about 1800 and still continues, the note book kept by the decorator Henry Daniel records the following recipe under the date 1816:

\section{New Gold Made out for Mr. Hancock}

'Dissolve an Ounce of Gold in Aqua Regia, precipitate with a Strong Solution of Copperas [ferrous sulphate] as filtered then wash your precipitate of Gold well then dry it. When dried pour upon it some Spirits of Salts to take the Iron out should there be any then wash it well again. Dry it perfectly, then to the Ounce of Gold add 15 pennyweights of Quicksilver and 20 grains of Magister of Bismuth. Grind for use'.

A slightly more picturesque recipe preserved in the archives of the Minton factory, founded in 1796 at Stoke and also still operating most successfully, is the following, dated 1824:

'Take Gold an Equal quantity an Quicksilver an equal quantity rub them in an Stone Mortar untill you have rub the Silver and 


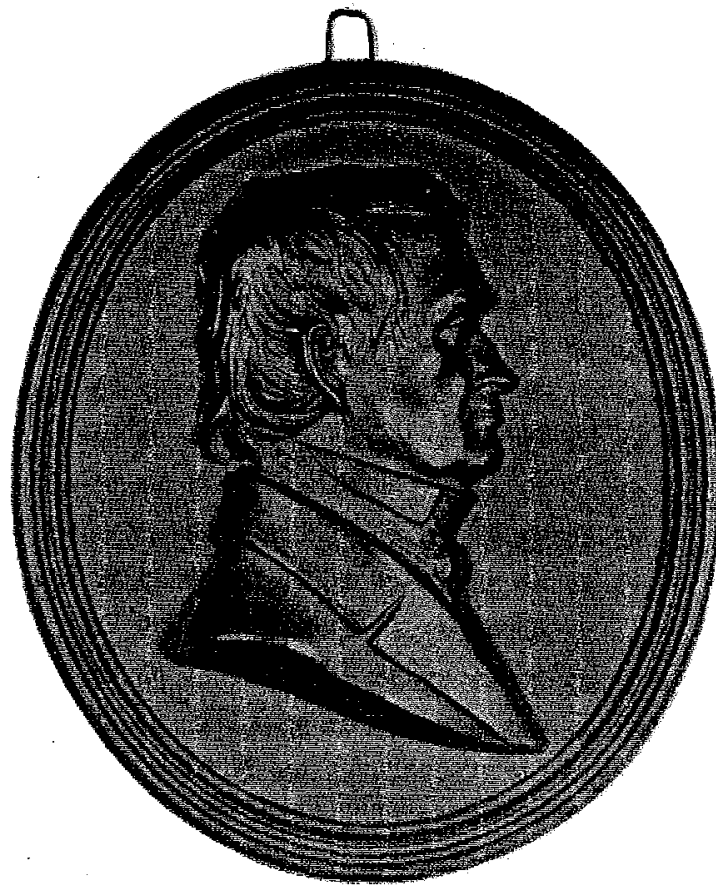

Heinrich Gottlob Kühn

A commemorative plaque made at Meissen depicting Kühn as a young man. Trained as a metallurgist, he came to the factory in 1814, and was a director from 1849 until his death in 1870. After a lengthy series of experiments he was successful in developing a liquid preparation for the gilding of porcelain and although this yielded an extremely thin and not very durable gold coating it none the less formed the basis of all subsequent preparations

Gold together then divide it in grinders it will take about $1 / 2$ an hour to rub a $1 / 4$ of an $\mathrm{Oz}$ of each this is the Gold most used at the present time 1824 as Grain Gold as desolved by fire and is wirksome to the eyes and teeth' (6).

\section{The First Liquid Gold Preparations}

For the next major development in gilding technique we have to return to the Meissen factory. In 1814 Heinrich Gottlob Kühn, who had been trained as a metallurgist at the mining academy at Freiburg, was appointed as technical manager there, the works having just re-opened after its closure in 1810 during the Napoleonic wars. Economy was essential, and among other activities Kühn embarked on a long investigation to find a cheaper means of gilding. Not until 1827 , however, did he finally succeed in evolving an entirely new method, one that laid the foundations of the procedures still in use today as well as being of great value to Meissen and its future development.

Unlike all other gilding media so far employed, Kühn's preparation was in liquid form and could readily be painted on to the ware. It consisted of a solution of gold chloride in 'balsam of sulphur', an oily substance obtained by reacting sulphur with turpentine. This medium - of somewhat uncertain chemical composition - had been known for very many years and is described, for example, by Neri in ' $L$ 'Arte Vetraria' of 1612 and by many later writers of hand-books and encyclopedia. It had been rather tentatively employed by Staffordshire potters, including Spode and Wedgwood, as a basis for a thin lustre by about 1812, but a full and precise recipe appeared in 1824 when the widow of Thomas Lakin, for some time a partner in Lakin and Poole in Staffordshire and later manager of the Leeds pottery, published a book containing all her husband's recipes, to the great annoyance of the pottery industry (7). In his Process 102 , Lakin described the preparation of a gold lustre by mixing a rather dilute solution of gold in aqua regia with balsam of sulphur to give the pink or purplish colouration normally associated with gold in low concentration.

A few years later, there appeared in Nürnberg a small book of recipes for the decoration of pottery and porcelain in which Lakin's procedure was reproduced (8). The authorship is uncertain, but is believed to be that of one Sebastian Leibl, while the second and improved edition, published in 1829 , is alone extant and it has been impossible to trace the first edition or its exact date.

It seems, however, highly likely that Kühn at Meissen was familiar with this work, and that he started from Lakin's formula to obtain a truly metallic deposit by increasing the gold content of the solution. At all events he succeeded for the first time in producing a liquid preparation which, on firing at a relatively low temperature, yielded a bright and shining gold that needed no burnishing or polishing. The gold was, however, extremely thin and its durability left much to be desired. By about 1836 , nevertheless, the preparation had been improved, and Kühn could claim that Meissen produced the best and most durable gold that could be fired together with the enamel colours (9). This became known as 'Glanzgold' in German, or 'liquid bright gold' in English, terms still used today for the greatly improved modern preparations.

The secret process, although closely guarded at Meissen, inevitably leaked out, first to Paris where two brothers named Dutertre managed to secure a French patent, No. 5336 of 1850 , with an additional specification in 1861 , for virtually the identical process used in their decorating establishment in the Rue d'Angoulême-du-Temple. Their process was submitted for examination by Alphonse-Louis Salvetat, then chief chemist at Sèvres, by the Sociêté d'Encouragement pour l'Industrie Nationale, and received a glowing recommendation from this well-informed expert. 


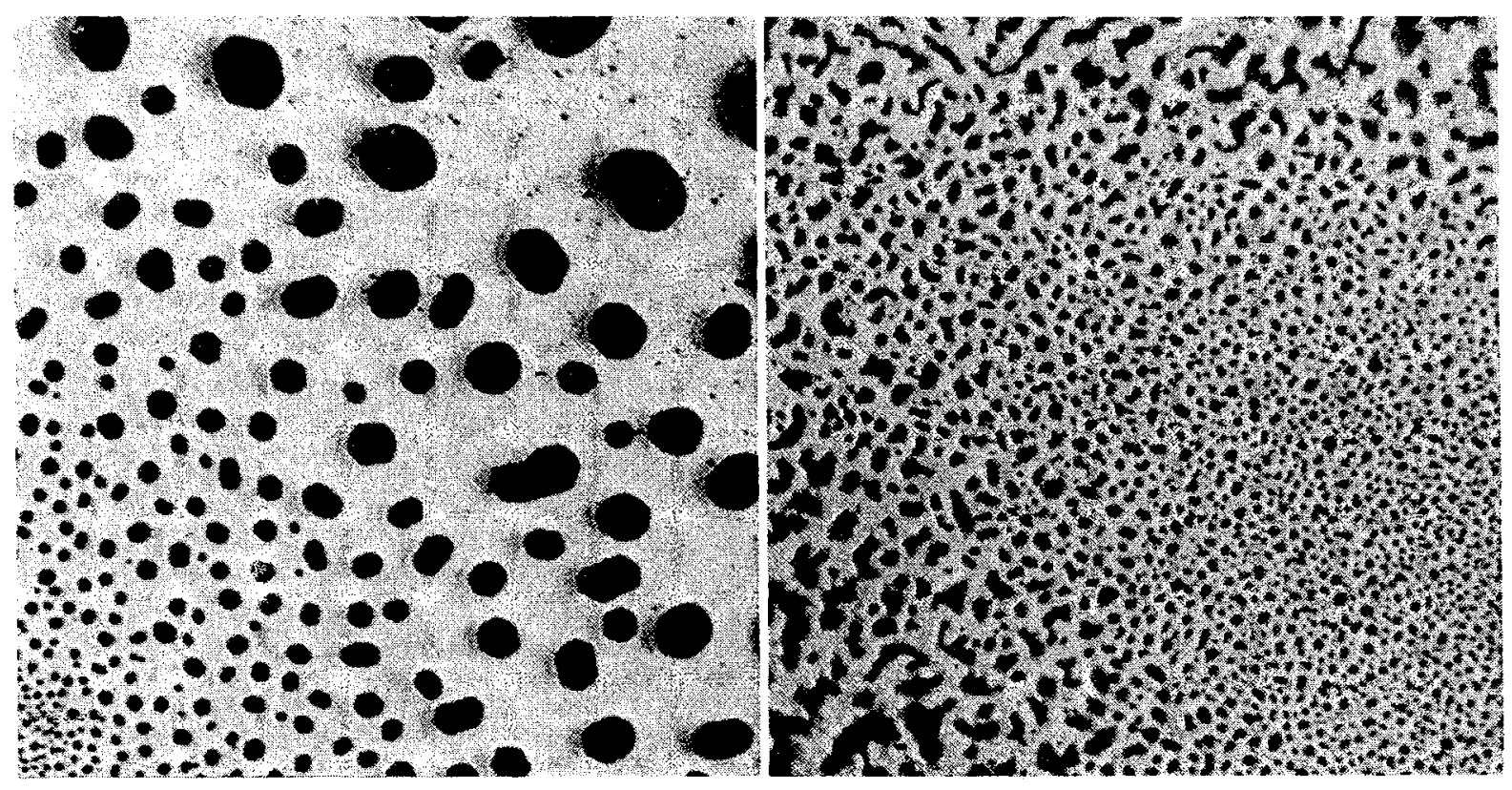

The importance of incorporating base metal additions such as bismuth, cobalt and chromium into liquid gold preparations to improve adhesion was recognised in the 1850's, but a further vital factor in ensuring the formation of a continuous film of gold was found to be the presence of a very small percentage of rhodium to reduce surface tension. These electron micrographs, taken some years ago by Dr. Alfred Boettcher, at that time Director of Research at Degussa, show on the left, at a magnification of 10000 , a liquid gold preparation without rhodium addition lired onto porcelain at $850^{\circ} \mathrm{C}$, compared with, on the right, a commercial liquid gold fired at the same temperature and again shown at 10000 magnifications. The thickness of application was intentionally varied, but it is clear that the presence of rhodium has had a marked effect in avoiding agglomeration of the gold particles during firing

The Dutertre workshop was then said to be using some four kilograms of gold each month and employing five hundred workers (10).

Similarly in Germany, the Meissen gilding method reached other interested parties outside the factory and, by way of two brothers named Schomburg in Berlin, it fell into the hands of a professor of mathematics and chemistry at Passau named Christoph Bergeat. A man of restless energy and a tireless experimenter in the laboratory in his kitchen, Bergeat, among other investigations, carried out a long series of experiments to find an improved form of Glanzgold that could withstand the muffle temperature used for colours. In this he was successful by 1858 and, after handing over his business to his eldest son, he died in 1888 leaving a considerable fortune (11).

Bergeat was followed by a company in Nürnberg, C. Leuchs and Co., engaged in a variety of activities including the merchanting of soap and candles and later the manufacture of perfumes. By 1875 they were supplying a liquid gold to the porcelain and pottery industries that was characterised by an exceptionally good resistance to firing (12).

In England, in 1878, George Matthey provided the Minton porcelain factory with a number of samples of liquid gold preparations with apparently limited success, and the lead in this line of business now passed to the Roessler brothers, Hector and Heinrich, and their company, Die Deutsche Gold- und SilberScheide-Anstalt, established in Frankfurt in 1873. In his memoirs, Heinrich, the younger brother, records that in 1878 they were offered by one Maurice Philipp, a Roumanian, a process for making liquid gold that had been devised by Dr. G. C. Wittstein, a private tutor in chemistry in Munich and a prolific compiler of chemical and pharmaceutical recipes. Roessler had little success with this, but his interest was aroused and he proceeded to have analyses made of the 'Passau' gold of Bergeat and the 'Nürnberg' gold from Leuchs. (These identifications remained in use for many years after the original producers had ceased operations). In Bergeat's product, 'small amounts of bismuth, chromium and cobalt were detected, designed to assist in adhesion of the gold film, but nothing of this kind could be found in the superior liquid gold from Leuchs. Then, on a visit to Johnson Matthey in London, Heinrich mentioned his difficulties in competing with the Nürnberg firm, only to be told that they, Johnson Matthey, were rather puzzled by Leuchs' regular purchases of small quantities of rhodium chloride, at the time a rare and little known compound. This gave Roessler the clue he needed, and by 1879 he was producing a reliable liquid gold fully as good as that from Leuchs.

This was the first entry into the gilding of porcelain and pottery by an established refiner and fabricator, equipped with a comprehensive knowledge of the 
chemistry of gold, and in 1885 satisfactory arrangements were made with both Bergeat and Leuchs to take over their products and processes. The Roessler company, nowadays known of course as Degussa, gathered up all the recipes, solved the problems of stability that had often bedevilled users, and thereafter became the leading producer for a long period of years, supplying the products not only from Frankfurt but from a small plant set up in New York in 1885 (13).

The vital importance of the small content of rhodium, necessary to reduce the surface tension of the gold and to ensure the formation of a continuous film, is illustrated in the electron micrographs on page 125, taken some years ago in the Degussa research laboratories.

\section{Modern Formulations}

Thus commercial production of liquid golds had begun, and other gold refiners in Germany, Holland, England and France very soon embarked on similar activities. The liquid bright golds were followed by the liquid burnish golds, containing a proportion of gold powder held in suspension and giving a much thicker deposit but with a matt finish that must be burnished.
The basic compositon of liquid golds was now established, but a great deal of research and development has of course been carried out over the years by all the interested manufacturers and many refinements and improvements have been introduced to meet the needs of individual users. An extensive range of products is thus available, varying in gold content, in colour, in thickness and viscosity, and in suitability for the more exacting requirements imposed by mechanical means of application. The production of finer and more controlled gold powders, together with the use of synthetic resins and other organic media, have made possible great advances in the technology, in ease of firing and in resistance to wear of the gold decoration.

\section{Methods of Application}

Traditional methods of application by hand brushing remain, while stamping and spraying are also employed, but for economical quantity production ingenious machines have been developed to apply both bright and burnish golds to the ware, particularly for banding and lining but also for the direct screen printing of designs. The preparation of liquid golds for machine application presents certain problems, however, since their viscosity must not change

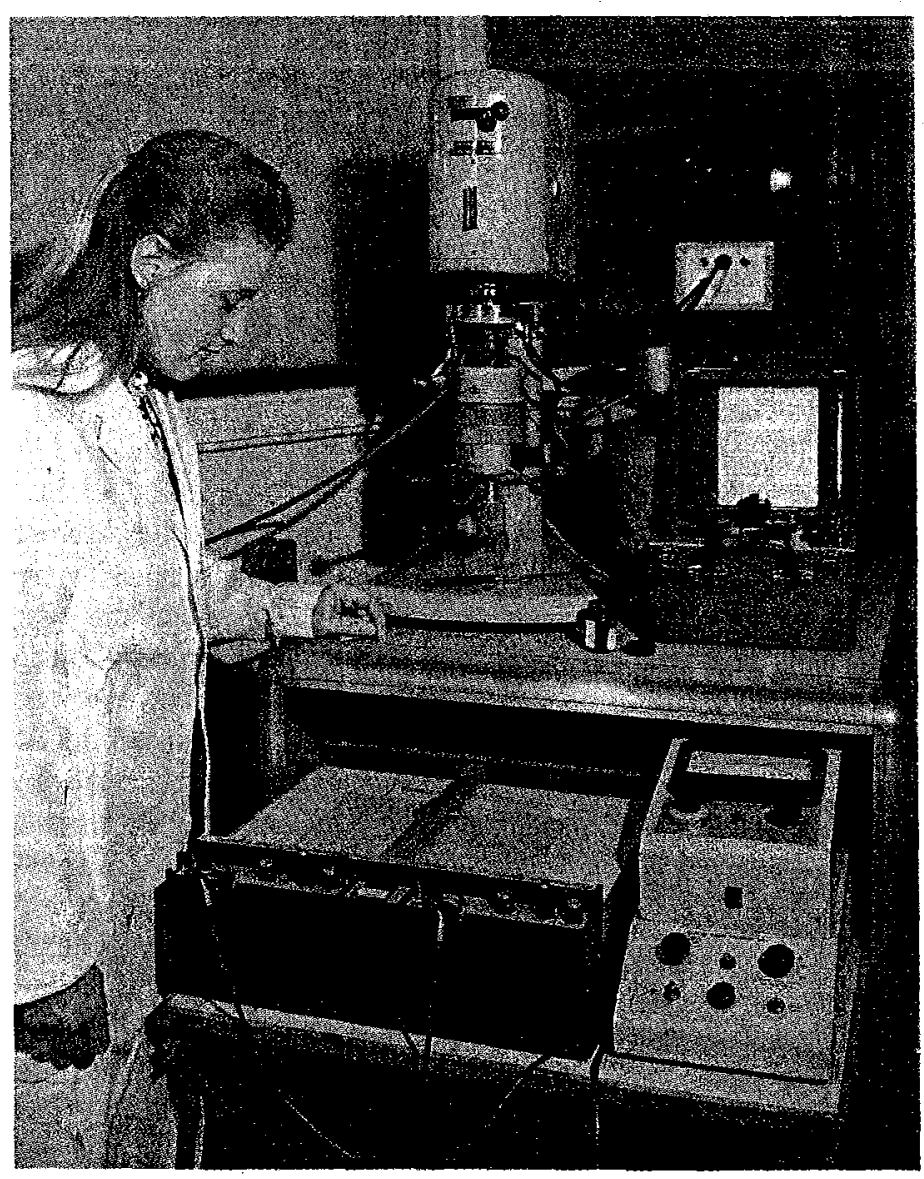

Moderin liquid gold preparations can be applied to the ware to be decorated by a variety of mechanical methods, as well as by hand painting. They are therefore produced in a range of forms from thin liquids to thick pastes in order to be suitable for one or other of these methods, and the measurement and control of their viscosity and other rheological properties are necessary both in experimental work and in production. One of the instruments used for this purpose is the Ferranti-Shirley viscometer in which a specimen is subjected to controlled shear between a rotating cone and a stationary plate at constant temperature. Rheological characteristics are then calculated from data on an X-Y recorder, obtained either by programming the machine to give a plot of stress vs. rate of shear, or by the study of timedependent effects from the hysteresis loop obtained by an acceleration-deceleration of the cone from and to zero 
Nowadays, the application of liquid bright gold or liquid burnish gold is often carried out by machines specially designed for this purpose. In this operation in the Worcester Royal Porcelain factory, the liquid gold - a recently developed product from Johnson Matthey containing synthetic resins and waxes - is fed to the ware from a heated reservoir and dries immediately. The new preparation gives a thicker deposit of gold than is obtained with cold application and permits faster decorating speeds. The machine was designed and built by F. Malkin and Company of Stoke-on-Trent

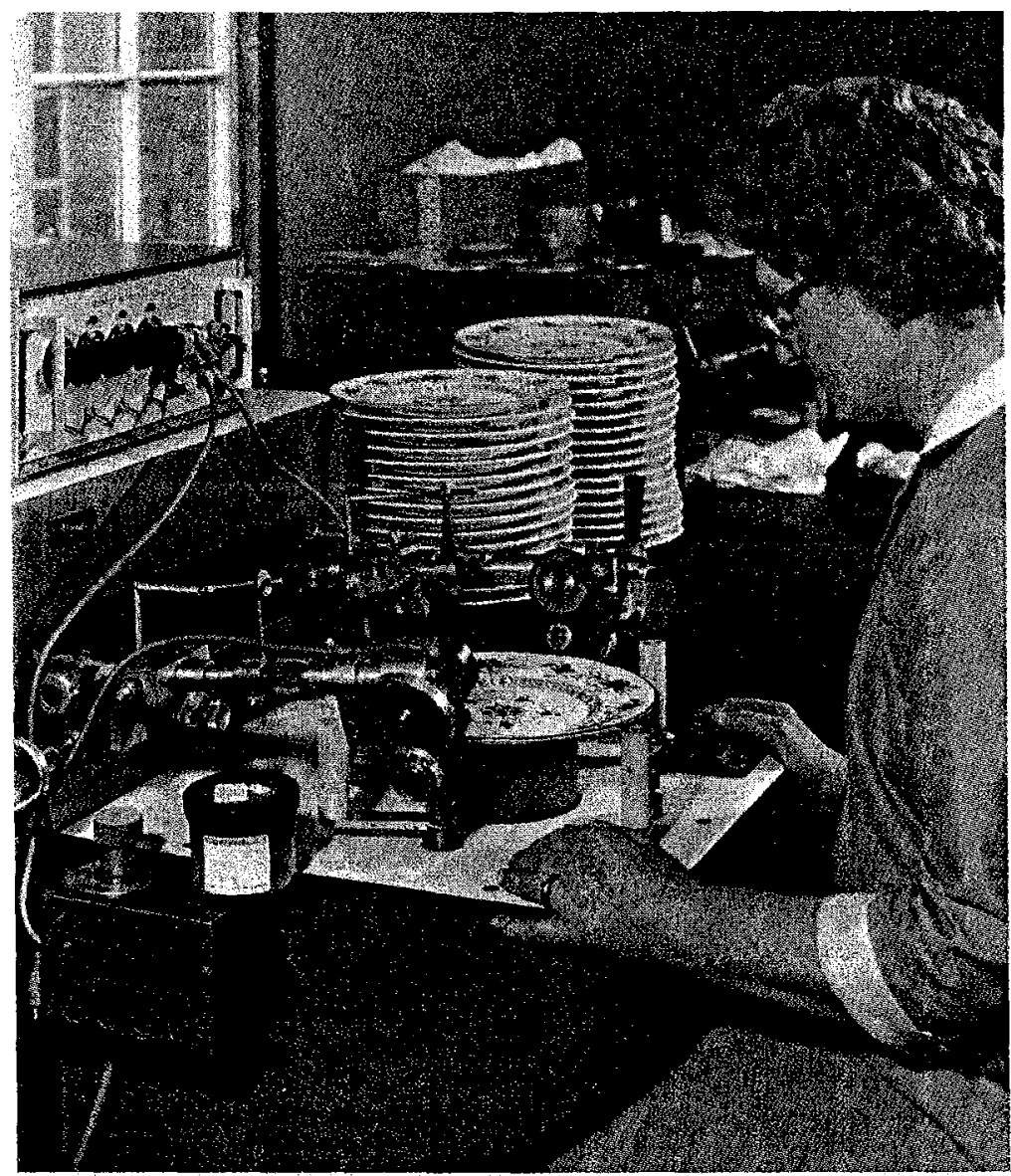

too rapidly despite continual exposure to the atmosphere and yet they must dry sufficiently quickly to enable the decorated ware to be handled in the unfired state. The speed of evaporation of the volatile constituents must therefore be carefully controlled in order to ensure the best possible results under production conditions.

Where intricate patterns or designs are to be produced in gold the preferred method is to use silk screen transfers, which give a decoration of higher quality than can be achieved by any other method of application. In this process the pattern is reproduced photographically on a stencil supported on a fine silk or stainless steel mesh, and the gold preparation is forced through the stencil on to gummed paper. All types of liquid and burnish golds can be used on silk screen transfers, together with enamel colours, to produce rich and detailed designs in relief and to yield in one firing well defined patterns that were formerly unattainable except by skilled hand painting.

The incorporation of certain types of synthetic resins and waxes has recently enabled the user to lay down thicker deposits of gold more quickly, while the introduction of refractory-stabilised gold powders has also been effective in permitting firing at higher temperatures for shorter periods.
Acknowledgements

The writer has benefited greatly from advice and information generously provided by the late Dr. Martin Mields, formerly Technical Director at Meissen, Dr. Schärer, archivist at Meissen, Madame T. Préaud, archivist at Sèvres, Mrs. Una des Fontaines, Herr Gert Becker and Dr. Max Kollmar of Degussa, Dr. Ian Fraser, Librarian at the University of Keele, Mr. Hugh Tait of the British Museum, and from his colleagues Mr. F. E. Kerridge, $\mathrm{Mr}$ O. N. Collier and Mr. C. Hood.

\section{References}

1 Jean Hellot, Registre Y49, in the archives at Sèvres

2 J.J. Bachelier, 'Mémoire Historique de l'origine du régime et des progrès de la Manufacture Nationale de Porcelaine de France', Paris, 1781, 25

3 Alexandre Brongniart, 'Traité des Arts Cêramiques', Paris, 1844; 2nd edition, 1854, II, 601

$4 \mathrm{M}$. Jean d'Albis, Limoges; private communication

5 Wedgwood Archives, Keele University Library, 25: 18073, 18083 and 18089

$6 \mathrm{Mr}$. Hugh Gibson, Royal Doulton; private communication

7 Thomas Lakin, 'The Valuable Receipts of the late $\mathrm{Mr}$. Thomas Lakin', Leeds, 1824, 58

8 Sebastian Leibl, 'Mittheilungen für Töpferein, Porzellan, Fayance und Steingutfabriken', Nürnberg, 2nd edition, 1829, 7

9 Karl Berling, 'Königlich Sächsische Porzellanmanufaktur', Meissen, 1910, 128

10 A. L. Salvetat, Bull. Soc. d'Encouragement pour L'Industrie $\mathrm{Na}$ tionale, $1861,8,129$

11 Dr, Lingen, City archivist, Passau; private communication

12 Dr. G. Hirschmann, City archivist, Nürnberg; private communication

13 Heinrich Roessler, 'Geschichte der Arbeitsmethode der Scheideanstalt', Frankfurt, 1903, 46 